\title{
Treasured trash? A consumer perspective on small Waste Electrical and Electronic Equipment (WEEE) divestment in Ireland
}

Article

Accepted Version

Creative Commons: Attribution-Noncommercial-No Derivative Works 4.0

Casey, K., Lichrou, M. and Fitzpatrick, C. (2019) Treasured trash? A consumer perspective on small Waste Electrical and Electronic Equipment (WEEE) divestment in Ireland.

Resources, Conservation and Recycling, 145. pp. 179-189. ISSN 0921-3449 doi:

https://doi.org/10.1016/j.resconrec.2019.02.015 Available at https://centaur.reading.ac.uk/89551/

It is advisable to refer to the publisher's version if you intend to cite from the work. See Guidance on citing.

To link to this article DOI: http://dx.doi.org/10.1016/j.resconrec.2019.02.015

Publisher: Elsevier

All outputs in CentAUR are protected by Intellectual Property Rights law, including copyright law. Copyright and IPR is retained by the creators or other copyright holders. Terms and conditions for use of this material are defined in the End User Agreement. 


\section{CentAUR}

Central Archive at the University of Reading

Reading's research outputs online 


\title{
Treasured Trash? A Consumer Perspective on small Waste Electrical and Electronic Equipment (WEEE) Divestment in Ireland
}

\author{
Katherine Casey ${ }^{1}$, Maria Lichrou ${ }^{1}$ and Colin Fitzpatrick ${ }^{2}$ \\ 1 Department of Management and Marketing, Kemmy Business School, University of Limerick \\ 2 Department of Electronic and Computer Engineering, University of Limerick
}

\begin{abstract}
Small Waste Electrical and Electronic Equipment (sWEEE) is a particularly problematic category of electronic waste. A growing body of research indicates that sWEEE tends to be either stockpiled or disposed of improperly (references). However, despite this, little attention has been given to the meanings people ascribe to their electronic and electrical possessions; meanings which continue to apply even when they are disused or broken. The purpose of this study was to generate insight into this area and to identify opportunities for intervention to increase sWEEE recycling. A quasi-ethnographic approach was used to investigate sWEEE disposal behaviour from the perspective of Irish consumers. The rationale for this approach was the need to reconcile the policy perspective on sWEEE with the subjective experiences and interpretations that drive people's behaviour. The findings reveal that from the time electronic and electrical devices enter consumers' lives until their disposal, they exist in fluid in-between states of meaning and have perceived value. Before divestment, sWEEE typically undergoes a four-stage journey: a) once electrical and electronic equipment (EEE) is no longer used, it tends to be either consciously stored or abandoned in the home (inactive EEE); b) a trigger prompts consumers to divest of the inactive EEE (critical moment); c) provoked to take action, consumers must decide precisely what to discard and how (transition from EEE to WEEE); d) consumers decide to recycle or not (divestment). The paper concludes by discussing the implications of these findings in terms of encouraging increased sWEEE recycling.
\end{abstract}

Keywords: small WEEE; consumer research; consumer experiences and interpretations; perceived value of WEEE; household WEEE divestment process 


\section{Introduction}

Darby and Obara's (2005) influential UK study into consumer attitudes towards small Waste Electrical and Electronic Equipment (sWEEE) highlights the problematic nature of sWEEE. A growing body of research indicates that sWEEE tends to be either stockpiled or disposed of improperly (Benton et al., 2015; Ongondo and Williams , 2011a; Speake and Nchawa Yangke, 2015; Wilson et al., 2017; Ylä-Mella et al., 2015). However, despite this, little attention has been given to the meanings people ascribe to their electronic and electrical possessions; meanings which continue to apply even when they are disused or broken.

The new (recast) WEEE Directive 2012/19/EU streamlined definitions set new targets and redefine WEEE categories, making sWEEE, as a category, more visible. The purpose of this study is to generate insights that may be used to identify interventions designed to encourage sWEEE recycling in order to make the WEEE Directive 2012/19/EU targets more achievable.

A quasi-ethnographic approach was used to investigate sWEEE disposal behaviour from the perspective of consumers. The rationale for this approach was the need to reconcile the policy perspective on sWEEE with the subjective experiences and interpretations that drive people's behaviour. The fieldwork took place in Ireland and consisted of in-depth interviews and observations.

The findings reveal that from the time electronic and electrical devices enter consumers' lives until their disposal, they exist in fluid in-between states of meaning and have perceived value. Before divestment, sWEEE typically undergoes a four-stage journey: a) once electrical and electronic equipment (EEE) is no longer used, it tends to be either consciously stored or abandoned in the home (inactive EEE); b) a trigger prompts consumers to divest of the inactive EEE (critical moment); c) provoked to take action, consumers must decide precisely what to discard and how (transition from EEE to WEEE); d) consumers decide to recycle or not (divestment). The paper concludes by discussing the implications of these findings in terms of encouraging increased sWEEE recycling. 


\section{Household WEEE}

Efficient infrastructure is indispensable to the success of recycling campaigns; however, consumers are the most important, dynamic and illusive element of WEEE recycling initiatives (Dwivedy and Mittal, 2013; Gurauskienè, 2008; Sivathanu, 2016). Researchers have tried to understand the barriers and motivations associated with consumer recycling behaviour and the determinants of consumers' disposal of their waste (Abeliotis et al., 2006; Martin et al., 2006; Pérez-Belis et al., 2017). Several prominent issues have been identified

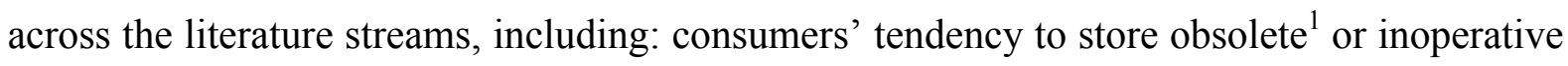
WEEE (Abeliotis et al., 2006; Ongondo and Williams, 2011a; Pérez-Belis et al., 2017; Saritha et al., 2015; Speake and Nchawa Yangke, 2015); consumers' willingness to pay for recycling or improved WEEE collection methods (Afroz et al., 2013; La Barbera et al., 2014; Nixon and Saphores, 2007; Song et al., 2016); consumers' willingness to recycle WEEE (Dwivedy and Mittal, 2013; B. Li et al., 2012; Nnorom et al., 2009; Saphores et al., 2006; Song et al., 2016; Speake and Nchawa Yangke, 2015); and consumers' willingness to pay more for environmentally friendly products (Saphores et al., 2007; Speake and Nchawa Yangke, 2015), which have all been explored in depth.

Thus far, with the exception of mobile phones, sWEEE has been neglected in the literature despite proving to be a significant WEEE stream. In Europe, large household WEEE represents the majority of WEEE in terms of weight; however, small and medium WEEE is more abundant and less likely to be disposed of responsibly. In 2015, the collection rates were as follows: 2.2 million tonnes of large household WEEE (52\% of the total WEEE collected), 639,984 tonnes of ICT equipment (17\% of the total WEEE collected), 599,050 tonnes of consumer equipment (15\% of the total WEEE collected), 368,493 tonnes of small household appliances (10\% of the total WEEE collected) and 267,355 tonnes of other types of WEEE (7\% of the total WEEE collected) (Eurostat, 2018). Given the range of products that fall into the sWEEE category, their short lifespan and the high incidence of such products in modern homes, the amount of sWEEE collected is low (Wilkinson and Duffy, 2003).

\footnotetext{
1 "Obsolete" does not necessarily mean that the products are inoperative, rather, that they are perceived as technologically lacking. These products are referred to as "end of use" equipment indicating their potential use value (Ongondo and Williams, 2011b; Ylä-Mella et al., 2015).
} 
Research suggests several possible reasons for this disparity, including a lack of awareness on the part of consumers of the recyclability of sWEEE, the perceived disproportion between individual disposal fees (Wilkinson and Duffy, 2003) and the fact that sWEEE is often disposable, not having been designed to be upgraded, repaired or reused (Darby and Obara, 2005). Consumers' use of informal collection channels may also explain the low collection rates for sWEEE (Martinho et al., 2017). The final relevant factor is the WEEE flow, that is, the time between the item becoming obsolete and being taken for recycling (Martinho et al., 2017). WEEE Ireland's latest environmental report (2017a) found that $80 \%$ of people have sWEEE or unused gadgets stored in their homes.

Within the broad category of sWEEE, mobile phones have emerged as being particularly problematic. In 2015, the number of stockpiled (or "hibernating") mobile phones was estimated to be between 28 and 125 million in the UK alone, with approximately $25 \%$ of retired mobile phones being recovered via take back schemes (Benton et al., 2015; Speake and Nchawa Yangke, 2015; Wilson et al., 2017). Research indicates that $85 \%$ of Finnish consumers store idle mobile phones despite knowing that they can be recycled (Ylä-Mella et al., 2015). Research exploring consumers' reasons for storing unused phones indicates that the most commonly cited responses to a question on this include "no reason", "as a backup", "it's obsolete", "because of its value" and, finally, "I do not know where or how to recycle it" (Speake and Nchawa Yangke, 2015; Wilson et al., 2017). Mobile phones and other devices capable of data storage can, for some consumers, capture various narratives to which they can become attached, and this emotional attachment can then influence their decision not to discard or recycle their cell phones. Whether this attachment is to the object itself or the data it contains is debatable (Welfens et al., 2016; Wilson et al., 2017). Ylä-Mella et al. (2015) and Ongondo and Williams (2011a) are consistent in their findings that $17 \%$ and 30\%, respectively, of their respondents, stockpiled their phones because they claimed to not know what to do with them, a finding which was further corroborated in the broader context of WEEE in a Jordanian study (Fraige et al., 2012). Thus, it is unsurprising that Speake and Nchawa Yangke (2015) found that, in relation to mobile phones, take back schemes are still underused; in fact, only $38 \%$ of their respondents were aware of take back schemes despite them being advertised on the Internet, in newspapers and on the television. 
Regardless of motivation, this is a problematic practice as mobile phones are a source of valuable secondary raw materials and constitute a hazardous waste stream (Speake and Nchawa Yangke, 2015). Mobile phones are often composed of over 40 metals, many of which are precious or critical raw materials (Ongondo and Williams, 2011b). Hence, although only $4 \%$ of mobile phones are disposed of via the general waste, they represent one of the most valuable electronic products present in general waste streams (Dalrymple et al., 2007; Speake and Nchawa Yangke, 2015). Additionally, technological advancement has increased electronics consumption and reduced the lifespan of various products, none more so than mobile phones, which have become the fastest growing piece of sWEEE (Speake and Nchawa Yangke, 2015). Meanwhile, Makov and Font (2018) discuss the rebound effect of smartphone reuse due to imperfect substitution between recirculated and new products and re-spending due to economic savings. They found a rebound effect of $29 \%$ on average.

Darby and Obara (2005) found that $26 \%$ of sWEEE is disposed of via the general waste, and although figures vary depending on the research context, there is consensus on this issue; Pérez-Belis et al. (2017) found that $90.84 \%$ of their respondents disposed of their sWEEE via the domestic garbage (only $6.63 \%$ recycled it) whilst a figure of $72.8 \%$ was reported in India (Saritha et al., 2015) and Abeliotis, Christodoulou and Lasaridi (2006) reported similar findings in Greece (82\%). The authors speculate that consumers may dispose of their sWEEE in this manner purely because of the item's size, which makes sWEEE easier to dispose of via the general waste (Darby and Obara, 2005). Consumer recycling habits are "notoriously difficult to change" (Darby and Obara, 2005, p. 25), and thus it is imperative that we develop a clear understanding of the barriers which must be overcome in order that the WEEE Directive is successful.

Consumers' reasons for EEE disposal has also attracted some research attention (Abeliotis et al., 2006; Dindarian et al., 2012; Gutiérrez et al., 2011b; Li et al., 2012). These studies have contributed to knowledge on barriers to recycling WEEE as well the quantitative/qualitative traits of WEEE, the lifetime of EEE and the hurdles to reusing WEEE (Pérez-Belis et al., 2017). Small EEE tends to last between four and eight years (Chi et al., 2014; Pérez-Belis et al., 2017), whereas larger EEE (refrigerators, televisions) often lasts longer (Gutiérrez et al., 
2011a). Research reports a myriad of conflicting reasons for EEE replacement, with malfunction and technological obsolescence commonly being cited (Afroz et al., 2013; Gutiérrez et al., 2011a; Islam et al., 2016; Saritha et al., 2015). This may be dependent on the appliance in question, for example mobile phones are very often replaced merely because service providers offer consumers an upgrade (Speake and Nchawa Yangke, 2015; Wilson et al., 2017). Consumers cite the cost of repair as the primary reason for opting not to repair EEE; some EEE products are simply cheaper to replace.

Research indicates that both suitable infrastructure and appropriate information are required if consumers are to successfully recycle (Byrne and O'Regan, 2014; Darby and Obara, 2005; Davies et al., 2005; Speake and Nchawa Yangke, 2015; Ylä-Mella et al., 2014). Davies et al. (2005) found that householders want more information about recycling. Consequently, recommendations for fostering positive waste management behaviour tend to include the provision of suitable information (Darby and Obara, 2005; Davies et al., 2005). However, content is important as respondents appreciate "appropriate" information. Darby and Obara (2005) clarify this further; their findings indicate that householders "do not want information on why they need to recycle, but are more interested in how they can recycle" (p.33, emphasis added).

A lack of consciousness in relation to sWEEE disposal has been reported (Darby and Obara, 2005; Wilson et al., 2017). Darby and Obara's (2005) respondents reported a lack of reflection as regards the disposal of sWEEE; many did not consider sWEEE to be "waste" akin to glass or paper, which had both been targeted by local authorities and required the ongoing participation of the public. In the same study, respondents claimed they were illinformed as to how to recycle sWEEE and also disclosed that they most often disposed of it via the household refuse or general waste (landfills) as charity shops did not accept it. Knowledge of how consumers can recycle WEEE and an understanding of the barriers to their participation in WEEE recycling will help determine the most suitable information to disseminate and make it possible to tailor recycling initiatives to specific households. There are many avenues which authorities can explore as to the information distributed, for example, several authors suggest that consumers need to be educated as to the possible 
negative environmental impact of WEEE (Abeliotis et al., 2006; Wang et al., 2011). However, caution should be exercised around this issue; Wilson et al's. (2017) participants reported that they had Googled "how to recycle phones" (p. 331), and the recent accessibility of such information may influence consumer recycling practices.

It has also been suggested that the development of appropriate infrastructure would increase participation (Darby and Obara, 2005; Davies et al., 2005). To address inappropriate WEEE disposal or storage, several authors have suggested financial incentives. This idea warrants more detailed research (Darby and Obara, 2005; Dimitrakakis et al., 2009; Pérez-Belis et al., 2017). Currently, WEEE is understood and researched as an independent waste stream. Darby and Obara (2005) call for an integrated approach, arguing that integration is necessary if the targets in the WEEE directive are to be met. Given that one of the most consistent findings in the whole research stream focuses on the "spill over" effect, it would seem that WEEE recycling should be considered in the context of general recycling.

Context seems to shape how consumers think about and behave in relation to WEEE recycling. First, research into attitudes and behaviours has concluded that pro-environmental attitudes do not necessarily translate into positive behaviour (the famous attitude-behaviour gap). This is evident in the existence of persistent irresponsible sWEEE disposal practices, including disposing of sWEEE via the general household waste. Second, institutional and structural factors affect individual behaviour. This is evident in the apparent difficulty so far in establishing consistent demographic characteristics across different studies. This raises the issue of context, as consumers' everyday disposition behaviour is dependent on the sociotechnical and cultural contexts in which this behaviour occurs.

\section{The Irish Context of WEEE Recycling}

The Irish WEEE producer's responsibility model was developed in response to the first WEEE Directive. The Environmental Protection Agency's (EPA) Office of Environmental Responsibility enforces WEEE and battery regulations in Ireland; in turn, local authorities enforce many retailer obligations. Household WEEE producers can fulfil their obligations either individually or through compliance schemes, which are operated by two producer responsibility organisations (Johnson and Fitzpatrick, 2014). 
Thus far, Ireland has achieved EU targets for collection, reuse, recycling and recovery of WEEE and is increasing its collection of WEEE (Eutostat, 2014; McCoole et al., 2014; WEEE Ireland, 2017b). In 2012, 40,818 tonnes of household WEEE were collected, amounting to $7.5 \mathrm{~kg}$ /capita. This figure increased to $8.073 \mathrm{~kg} /$ capita in 2014 , representing double the 2012 4kg/capita EU target and placing Ireland among the top 10 countries in the EU in terms of household WEEE collection rate (Eutostat, 2014). The target is due to increase to $65 \%$ of the average weight of EEE placed on the market in the previous three years by 2019 or $85 \%$ of WEEE arising. Ireland has, historically, met targets, with household WEEE collection rates close to the $65 \%$ target in 2015 and at approximately $67 \%$ in 2016 (WEEE Ireland, 2017b, 2016) (table 1).

Table 1 Household WEEE Collection Rates (based on data from WEEE Ireland 2015 and 2016 annual reports)

\begin{tabular}{|lll|}
\hline EEE Category & 2015 & 2016 \\
\hline Fridge/Freezers & $63 \%$ & $69 \%$ \\
Large Household Appls & $74 \%$ & $83 \%$ \\
Small Household Appls & $25 \%$ & $26 \%$ \\
IT\&T & $62 \%$ & $62 \%$ \\
Monitors & $638 \%$ & $231 \%$ \\
Consumer Equipment & $50 \%$ & $59 \%$ \\
TVs & $146 \%$ & $169 \%$ \\
Lamps & $43 \%$ & $38 \%$ \\
Luminaires & $36 \%$ & $33 \%$ \\
Tools & $19 \%$ & $40 \%$ \\
\hline
\end{tabular}

However, Ireland's collection rates are likely to fall as the collection of heavier cathode ray tube containing devices (CRTs) gradually declines as they are replaced by lighter flat screens. The same effect will likely be seen with regard to heavier desktop computers being replaced by lighter laptops and tablets. Thus the increased weight target may present a challenge. The high collection rate for large household appliances and fridge/freezers is also notable. Much of this is attributed to the new contribution schemes for electrical retailers to support storage 
and handling of the WEEE they take back and the marketing of free recycling services to customers. Ireland's WEEE recycling habits reflect those reported in the literature review. According to WEEE Ireland, only $30 \%$ of sWEEE was collected while $11 \%$ of people put sWEEE in the general waste and $80 \%$ of people hoarded waste and obsolete IT gadgets in the home (WEEE Ireland, 2017b).

\section{Methodology}

This study used a quasi-ethnographic approach to examine WEEE disposal from an emic perspective, which means from the participants' perspective or standpoint. This research tradition proposes that people navigate their lives in socially and culturally organised ways, using cultural knowledge as guidance (Atkinson, 2014). Understanding the cultural frameworks that underpin the relevant behaviour allows the ethnographer-analyst to see the world as the participants see it. This is achieved through observation and interview, with "participants' language, concepts, categories, and opinions" being used to guide the research and render the obscure visible (Ladner, 2014, p. 17). Emic research captures action, and not just reported action. Thus the researcher can move beyond the "attitude-behaviour" gap with the purpose of understanding "action in context" (Arnould, 1998). This approach seeks an understanding of human behaviour that is cultural and social rather than cognitive (Arnould and Wallendorf, 1994), recognising that people are not always reliable predictors of their own behaviour (Elliott et al., 2003). Particularistic rather than generalising in orientation, this type of research collects in depth or rich data via multiple methods in a specific context (Arnould, 1998). The purpose of this study was to develop insight into subjective consumer experiences with sWEEE and the meanings consumers attach to these objects.

Due to the scope of this study, it was not possible to conduct a traditional ethnography, which typically requires extended periods of observation of naturally occurring behaviour. WEEE disposal behaviour is infrequent and thus difficult to observe when naturally occurring. The research conducted was therefore quasi-ethnographic, involving short periods of observation of WEEE recycling at relevant sites and in-depth interviews at people's houses, which were supplemented by photographic documentation (where permitted). The fieldwork took place from September to December 2017 in the Munster region of Ireland. Data collection 
consisted of 26 in-depth interviews with 30 participants (table 2), observation at a CA site and waste collection event and participant observation at 25 retailers, ranging from those specialising in electrical and electronic equipment to supermarkets and homeware stores that distribute electrical and electronic products. Qualitative research samples are generally too small to facilitate the collection and analysis of in-depth accounts. Based on practice, Gaskell (2000) suggests that somewhere between 15 to 25 individual interviews is an appropriate number for interpretive analysis. As the goal of the research was not representativeness, the sample was selected intentionally by the researchers in order to reflect a range of household situations and experiences worthy of examination.

The interviews lasted from 40 minutes to 2 hours and took place in the participants' homes to allow observation of the sWEEE kept in the house and trigger participant reflection on their held sWEEE. Interviews were recorded with the permission of the participants. Care was taken to protect participant anonymity and ensure interview confidentiality. On four occasions two people were interviewed together, that is, three couples and a mother and daughter. Interviewing people who live together often generates dynamic insights, which help elucidate the household reality. Household reality is very often a shared reality "in which household activities and patterns are negotiated jointly (or certainly through interaction) and members mutually define themselves having some sense of shared personal history" (Valentine, 1999, p. 68). In addition, couples negotiate the stories which are told and they supplement or contradict the other's account, thereby generating rich and dynamic data (Bjørnholt and Farstad, 2014; Valentine, 1999). Couple interviews have some unique drawbacks; in particular, one partner may be more dominant than the other. This is especially relevant when interviewing couples about sensitive issues. This research was not particularly sensitive; however, care was taken to ensure equal representation. The participants were recruited from four counties of the Munster region: Limerick (19), Cork (6), Tipperary (3) and Clare (2). Our objective was to collect thick data to further an understanding of the phenomenon of divestment and not to accurately represent a population, and therefore, our data represents a range of different types of household situations (table 2). 
Table 2 Interview Participants

\begin{tabular}{|c|c|c|c|c|}
\hline Participant & Age & Occupation & Relationship Status & Notes \\
\hline Female 1 & 26 & Shop manager & Single & \\
\hline Female 2 & 36 & Teacher & In a Relationship & \\
\hline Female 3 & 30 & Software technician & Single & \\
\hline Female 4 & 28 & Engineer & Co-habiting & \\
\hline Female 5 & 29 & Project manager & Co-habiting & Interviewed with Male 1 \\
\hline Male 1 & 27 & PhD Student & Co-habiting & Interviewed with Female 5 \\
\hline Female 6 & 36 & Social worker & Single & \\
\hline Male 2 & 27 & Software developer & In a relationship & \\
\hline Female 7 & 26 & Student & Single & \\
\hline Male 3 & 32 & Mature Student & Single & \\
\hline Male 4 & 31 & Mature Student & Single & \\
\hline Male 5 & 25 & Trainee accountant & In a relationship & \\
\hline Female 8 & 60 & Retired teacher & Married, 3 adult children & $\begin{array}{l}\text { Interviewed with Female } \\
12\end{array}$ \\
\hline Female 12 & 24 & Student & Single & Interviewed with Female 8 \\
\hline Male 6 & 19 & Student & Single & \\
\hline Female 9 & 37 & Doctor & Married & Interviewed with Male 7 \\
\hline Male 7 & 35 & Accountant & Married & Interviewed with Female 9 \\
\hline Female 10 & 26 & Student & Single & \\
\hline Female 11 & 63 & Retired manager & Divorced, 2 adult children & \\
\hline Male 8 & 45 & Manager & Single & \\
\hline Female 13 & 55 & Carer & Married, 3 children & \\
\hline Male 9 & 31 & Engineer & Co-habiting & \\
\hline Male 10 & 37 & Lecturer & In a Relationship & \\
\hline Male 11 & 22 & Student & Single & \\
\hline Male 12 & 51 & Lecturer & Married, 5 children & \\
\hline Male 13 & 45 & Project manager & Married, 3 children & $\begin{array}{l}\text { Interviewed with Female } \\
14\end{array}$ \\
\hline
\end{tabular}




\begin{tabular}{|lllll|}
\hline Female 14 & 42 & Homemaker & Married, 3 children & Interviewed with Male 13 \\
\hline Male 14 & 42 & Engineer & Married, 3 children \\
\hline Male 15 & 45 & Engineer & Married, 2 children \\
\hline Male 16 & 30 & PhD Student & Single \\
\hline
\end{tabular}

Consistent with the aim of ethnographic interviewing to elicit detailed subjective accounts in which people make sense of their own and others' behaviours (Arnould and Wallendorf, 1994), the interviews were conducted as a "series of friendly conversations into which the researcher slowly introduces new elements to assist informants to respond as informants" (Spradley, 1979, p. 58). In doing so, the interviewers enquired about the participants' personal circumstances and interests, their relationship with technological products, their awareness of sWEEE, their most commonly used devices, their memories of old devices and their journey, their experiences with the disposal of electronics, their awareness of WEEE policies and, finally, their attitudes towards recycling in general. The purpose was to obtain rich holistic accounts of participants' experiences in relation to WEEE.

While with ethnographic research the interpretation of data begins in the field (as patterns are observed during fieldwork), systematic analysis started once the fieldwork was completed. Rich textual data was produced from the interviews and observations in the form of interview transcripts and field notes. The interviews were fully transcribed, generating 680 pages of text. The data was analysed thematically to identify important meanings around WEEE disposal as well as any disjuncture in the participants' stories, revelatory moments and behavioural regularities (Arnould and Wallendorf, 1994). The researchers formed an interpretive team and compared and contrasted themes with each other to refine the initial analysis. 


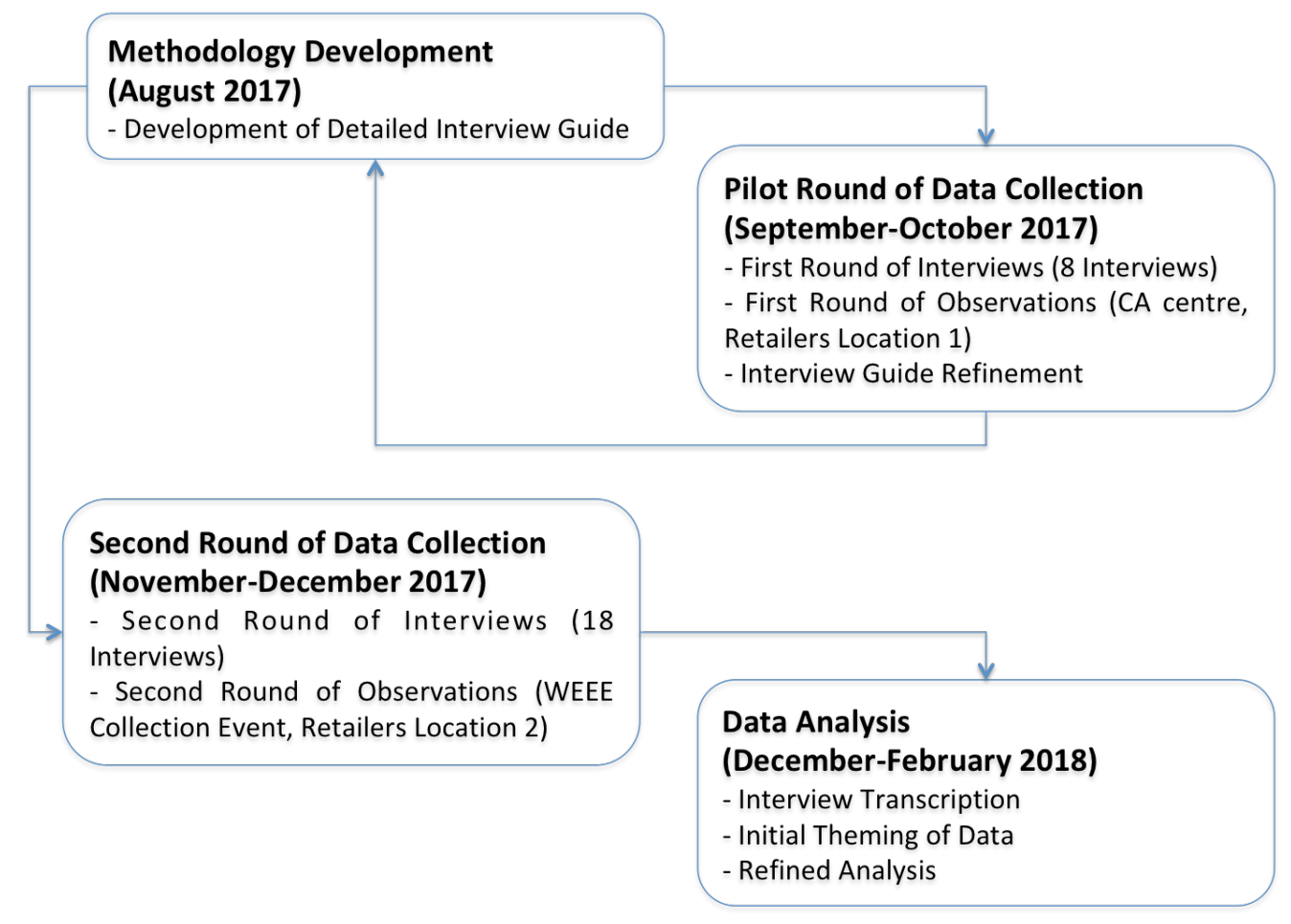

Figure 1 Fieldwork and Data Analysis

\section{Findings: Consumers' Experiences with WEEE}

The findings reveal that the clear-cut categorisation of EEE and WEEE is, unsurprisingly, far removed from consumers' use and understanding of electrical and electronic possessions, even more so in the case of sWEEE. The participants do not view their disused or even unwanted EEE as "waste" but rather as "stuff". Furthermore, for consumers, electronic and electrical devices exist in fluid, in-between states of meaning and perceived value from the time they enter their lives until their disposal.

\section{WEEE "Lurking”: Abandoned Electronics}

Once EEE falls into disuse, whether it is damaged, broken, replaced or obsolete, the participants tend to just abandon it; so unwanted EEE "lurks", as one participant remarked, behind picture frames, hangs from shelves and hides in drawers "somewhere in the abyss" (figures 1 and 2).

Female 7: It's in a vase in my house, in my Mum's house. I don't know. I didn't put it there. I brought it home, and I said 'this is useless to me now that I have got a new phone'. I think 
that I just left it on the counter one day, obviously probably not where it was supposed to go, but somehow it ended up in a vase in the kitchen.

This participant's description is indicative of how the participants approach this recurring problem. Unwanted EEE is essentially abandoned, not consciously stored; instead it takes its place amongst other unwanted, homeless items, such as past Christmas cards, lockless keys and old bills. Unwanted EEE is not only stored with other objects but also with broken EEE. A recurring theme was an expressed uncertainty in terms of dealing with particular items. This is especially true of cables, "peripherals" and "components", which, once disused, quickly melt into the domestic landscape; they disappear into drawers and slip onto shelves. This is possibly because small EEE can be stored so easily. Very small EEE is particularly problematic as not only is it easily stored, the participants struggled to categorise it, which led to confusion about its disposal:

Female 9: What if it's a component, not even a full thing? You know, a bit of a wire or something, or a thing, and you are thinking, you know...

Despite lacking value, peripherals are often stored mainly because they are difficult to categorise. Cables are ubiquitous, received in some form with almost every technological device, they seem to consume drawers and shelves.

\section{Consciously Stored EEE}

Consciously stored EEE is put somewhere intentionally and neatly. For example, different participants exhibited the following behaviours: carefully packing spare or back-up electrical devices in a convenient bag (Female 7, figure 4), keeping unused equipment in a dedicated room in the house, where EEE is arranged as if it is still being used (Male 8, figure 5), and using plastic boxes and appropriately sized ice-cream containers to organise collected EEE (Male 7, figure 6). Many of the participants appeared to be conscious of this habit, referring to the behaviour as "hoarding" (figures 3-8). Storage is time-consuming because it requires thought and space. The research found two major factors underlying the conscious storage of EEE/WEEE. 
Use potential was the most commonly cited reason for conscious EEE storage. The participants expressed the belief that their old EEE would, at some point, be useful, that it would serve as a backup in an emergency or serve some unforeseen purpose or that it might be valuable to another person. Once use potential has been identified, that object retains or even regains value; this is evident in how the consumers treat these objects:

Male 2: The [bits of an old PC] are currently stored in a box to go to my brother-in-law, who really wants to get into playing PC games. He is after going back to College as well and works in [name of fast food store] and doesn't have the money to do it. So, I am waiting to get one or two final pieces and then give him the machine. If he will get the use out of it rather than it going to a landfill or trying to make sure that it gets recycled properly like, it's way better.

A recurring theme was storing WEEE with use potential on behalf of members of their social network (with or without their knowledge). EEE moves through social networks until it is defunct.

Male 12: You know, I could actually tell you where our old video player is. It's in my parents-in-law's house over in Wexford [some $200 \mathrm{~km}$ from the participants home]. Researcher: And do they use it?

Male 12: They don't. [...]

Researcher: Why didn't you recycle it?

Male 12: Because my brother-in-law is a dab hand with doing, kind of, nifty things, like converting video to DVD.

Despite the space and energy required to store EEE, it is often stored for several years, eventually becoming obsolete, entombed it is forgotten. This is especially the case when backup cables and components are stored for technology that becomes obsolete. The findings suggest that consumers store old EEE as backup regardless of whether they think it will be of use in the future. This kind of conflict was prevalent in the interviews; the participants expressed awareness of the futility of keeping old EEE and were even somewhat critical of 
their own hoarding, yet they are loath to discard what they perceive as being potentially useful EEE. They mentioned that parts from broken electronics can be dismantled and repurposed as a part of something else and technical skillsets can be appropriated to convert damaged parts into useful oddments.

Male 9: I would probably take the fuse out of it first because fuses are handy. If a fuse breaks in a lamp, you can have another one. So, I would take the fuse out of it. Anything else really that's on it is not going to be much good to me like.

Male 5: Well, the desktop, I took all the, I used it so much that it died, so I took all the functioning parts, like the ram and hard-drive out of it and put it in my new computer. Researcher: Did you know how to?

Male 5: Well, I suppose the Internet told me. Like, YouTube, yeah. I just YouTubed and it told me how to do it. YouTube has step-by-step tutorials and all those things, so I just did it.

Whether or not the participants actually are aware of the perceived potential of WEEE does not determine whether they keep their "stuff". Discarding objects laden with untapped potential is seen as wasteful and therefore undesirable:

Female 4: I do feel sorry because I think that someone can use it [an old incapacitated laptop].

2) Emotional Attachment was sometimes experienced in relation to specific items. The participants described an emotional connection to forms of data (photographs, music, messages) stored on particular pieces of electrical equipment, such as laptops, phones or cameras.

Female 6: I have my, that's my second laptop, my first one, which I had when, like fifteen years ago, or something, I don't know, is in probably, probably in the shed, because I have loads of information on it, loads of music from like back in the day, and I want to get it taken off. I just haven't brought it to anyone to do it. 
Connected to this theme, data transfer emerged as an issue for some of the participants, and several of them described the importance of data protection.

Male 15: I have hard-drives. Yeah. A drawer full of hard-drives upstairs and everything else. I don't know, I probably should just smash them up. My logic was that if I put the hard-drive down, I could have data there or anything. I wouldn't have a lot of sensitive data, but maybe bank records, correspondence on savings and that type of stuff, alright. I suppose all your emails around insurance, house, you know, all that type of private stuff. So, yeah, I have held onto hard-drives.

Furthermore, a few participants described feeling an emotional attachment to a particular device. However, these feelings are limited to single objects, which hold special meaning for these consumers.

Female 1: I haven't even thought about [recycling an old laptop]. I have to at some point, when I want to get rid of the laptop, but I think I've just got a special attachment to it, maybe because it was my laptop during College. I don't know. It is very, very, old like.

\section{Confronting WEEE}

Another key theme was particular events in the participants' lives or triggers that prompted a critical evaluation of both consciously stored and abandoned EEE kept in their homes. Such "critical moments" that prompt heightened reflexivity around WEEE are likely to occur under specific conditions.

Male 3: I did a clear out in January for various reasons. I was at home, and I was unemployed, and I was trying to plan my life, and one thing I noticed I have all this crap I don't need [...] and then I had 2 bags pretty full of stuff [...]. I just looked up where to bring them [...], and I just brought them there. It was free.

Life transitions often trigger these critical moments. Moving is often in itself a sufficiently 
powerful event to awaken this kind of reflexivity. Change in general is often a catalyst for divestment. Several participants described the renovation of their homes as a time when they had or would take the time to discard old EEE.

Female 11: I had reason to pull everything out of the attic, but the guy who was doing it, there were things like...there was a radio-cd player, a few things like that, but he took them away and recycled them. But I presume he was recycling them. He said he was taking them to the dump.

Finally, an external trigger can also elicit a critical moment. For instance, several participants discussed their tendency to donate certain kinds of EEE, especially mobile phones, to charity. At one point, one participant donated all of the phones he had collected to support a family friend's fundraiser. Other participants reported similar activity; several specifically mentioned a phone recycling initiative run in Ireland until 2016. Similarly, participants spoke of the old "rag and bone" man who they would give their WEEE to were he still around.

\section{Trash or Treasure?}

Once the participants have decided to divest of some of their electronics, they still engage in a complex process of determining which of their devices to do this with. These objects have transitioned from EEE to WEEE in the minds of the consumers and have lost their perceived value.

Male 1: Well, half the screen stopped responding to touch, so I could have got it repaired, but the phone was probably not worth the value of the repair at that stage, so I got a new one.

This decision is particularly difficult for the technologically skilled. For example, one participant (Male 2) defined himself as "someone that always tries to give new life to old hardware" and was thus somewhat dismayed at the thought of discarding his old device, despite not knowing its whereabouts or whether it is still functional. Another (Male 12) stores old EEE on behalf of his brother in law, thereby avoiding a difficult decision. This kind of complexity is evident throughout the interviews, with other participants also struggling with the notion of discarding old devices. 


\section{Disposing of WEEE}

With a few exceptions, almost all the participants had engaged in some form of WEEE recycling, typically the exchange of large WEEE on replacement. However, when smaller WEEE was divested, several of the participants reported using the general waste bin. As a direct corollary of a prevalent lack of consciousness around sWEEE, the inclusion of peripherals or components in the WEEE category was unclear and, therefore, frequently a point of confusion. Consequently, when consumers reach this stage of the divestment process, they tend to err on the side of convenience. Regularly, peripherals are first ignored as a category of stuff (existing in space without real recognition). Then, they are not identified as a category of WEEE. Finally, they are often divested via the general waste.

All of the participants had some experience of the one-for-one exchange of large WEEE, and many of them were aware of the in-store equivalent. However, few could actually recall participating. The ethnographic aspect of this research explored consumer experience around bringing WEEE to larger stores for recycling and exchanging WEEE on a one-for-one basis in convenient stores. The findings reveal the process to be somewhat confusing and uncomfortable. This deduction is supported by the interview data:

Researcher: Would you bring stuff back to shops?

Male 10: Well actually, yeah, because they do recycle, don't they? If I thought about it, I would, but sometimes I might be dubious about whether they do or not or just chuck it into the same bin.

Another prominent theme involved issues of convenience and habitual practices, which the participants discussed as reasons for not recycling WEEE.

Female 2: I just don't get the time. You know, it's just one of these things. I just feel every day I'm working five days a week, and I get up, and I prepare for work, and I think about what to wear, and I go off to work, and I am an hour driving down and an hour driving back. I get a walk in, eat dinner, watch a bit of telly, and I'm tired. And I get up and do the same thing. It's just even, you know, it just seems hard to... These things, you see, like going to a recycling 
centre, or whatever, is a one-off. So when are you going to do that like? It's not going to be in your routine.

Collecting WEEE through retailers is dependent on consumers visiting the stores; very few of the participants described actually depositing sWEEE at a retailer, mainly because visiting retailers is an irregular event:

Female 3: I would probably bin it. What am I supposed to do with it so? Researcher: Well, you can bring it back to the shop. Like if you were to buy a new... Female 3: That's a lot of hassle, isn't it, instead of just throwing it in the bin. Going back to the shop. I don't know where the [...] kettle came from.

\section{Discussion: Mapping the household WEEE divestment process}

While policy frameworks and the academic literature treat obsolete, inactive or broken EEE as waste, this is patently not reflected in the way people relate to these objects. The findings indicate that the participants do not distinguish EEE from WEEE, and especially in the case of EEE peripherals, such as cables and chargers. Additionally, they do not differentiate these from other non-electronic objects kept in drawers, sideboards and attics. Therefore, obsolete electronics cannot be treated as any other waste category. The intricate relationship between people and their possessions has been explicated by seminal consumer research exploring people's attachment to material (Belk, 1988; Belk et al., 1989; Kleine and Baker, 2004) as well as immaterial (Belk, 2013) possessions. Attachment to possessions is generally understood to underpin acquisition, consumption and disposal of goods, including collections, gift-giving, storing and divestment behaviour, which is often ritualistic in nature (Belk et al., 1989, 1988; Lastovicka and Fernandez, 2005; McCracken, 1986; Rook, 1985). Disposal of possessions is a process that facilitates the physical and psychological separation of an object from its possessor (Roster, 2001). Individual and social values, as well as the sentimental, economic and symbolic value attached to an object, influence consumers' disposal decisions (Albinsson and Perera, 2009). This is not different to WEEE related behaviour, as the findings of this study indicate. 
There is a body of consumer research which addresses the practice of disposal of meaningful possessions; however, recycling is generally not included. For example, Price et al. (2000) address objects which are distributed via direct transfer, via an intermediary and via the market. The movement of disused clothing from the main closet to a "transitionary space" before disposal is also documented (Hertz, 2011). In her study of the disposal of consumers' special possessions, Roster (2001) concurs that disposal is a process that facilitates the physical and psychological severance of an object from its possessor. Furthermore, similar to the "critical moment" found in this study, she describes how "critical events", such as life transitions, facilitate a change in the participants' understanding of the value of the object.

What is particularly interesting about sWEEE is that unlike other more definitively valued possessions, it exists in less visible and more fluid states. Its existence is patent, but somehow it simultaneously exists in the periphery of consciousness, "lying somewhere in the house" on shelves and in drawers. Thus, consumers treat disused EEE differently to other genres of recyclable material, and research which addresses this process is novel.

The issue of habit and convenience emerged as one aspect of consumers' experience with WEEE recycling. Defined as "the distance to a recycling station, the amount of space available to store recyclables, the ratio of collection bins to households or certain housing characteristics" (DiGiacomo et al., 2018, p. 310), inconvenience is cited as a barrier to both general household recycling and WEEE recycling (Bouvier and Wagner, 2011; DiGiacomo et al., 2018). The term can refer to structural facilities, practical arrangements inside the house or the preparation of household waste for recycling, each of which have been identified as problematic in relevant recycling literature (Bernstad et al., 2013; Martin et al., 2006). The concept of "convenience" would benefit from further elucidation. This research has examined how consumers interpret convenience in the context of everyday life. Convenience here is associated with the notion of routine, or lack thereof, in the WEEE recycling process. WEEE recycling as an activity is somewhat "irregular" for consumers. The first challenge arises from the fact that EEE does not break very often, nor is it often replaced (relative to other products that are consumed on a daily basis), and small and clean (W)EEE is easily avoided or ignored. Secondly, when WEEE has been identified and collected, it often remains in the 
home; consumers store WEEE or dispose of it incorrectly because electrical retailers and CA sites are not a part of their daily routine. Given these conditions, participants have not constructed a set of habits or routines around WEEE. The connection between WEEE recycling and routine is visible at every stage of the divestment process; the participants described habitually abandoning WEEE, routinely ignoring it until they encountered a critical moment, habitually storing obsolete EEE and overlooking unwanted EEE because disposing of it takes them out of their routine.

Based on the findings, it is possible to map out a four-stage process (figure 2) that reflects the life of (small) EEE after use.

- Stage one - Inactive EEE: Disused or broken electrical and electronic equipment kept in the home. When it is perceived to obtain utilitarian or emotional value, disused EEE tends to be carefully curated by the participants. Abandoned EEE, on the other hand, easily fades into the household landscape and is overlooked; this kind of EEE is not consciously kept. Additionally, because abandoned EEE is not valued, it is rarely the subject of debate or deliberate decision making. Over time, even the actively stored equipment is forgotten as its value dissipates. Additionally, consumers tend to overlook peripherals completely. Thus, consumers tend to ignore or store WEEE until doing so becomes more troublesome than recycling or discarding it.

- Stage two - Critical Moment: Life transition circumstances (such as moving and renovation) as well as some external triggers (such as charity campaigns) force confrontation with one's stored or hoarded possessions and reflection, and consequently, the consumers are propelled towards WEEE divestment. These triggers are critical moments that prompt reflexivity around the kept WEEE. Evidence of externally instigated critical moments demonstrates that these events can be purposefully prompted with appropriate interventions.

- Stage three - Categorisation: Following a critical moment, consumers must critically evaluate their possessions to decide which objects to divest and which to keep. At this stage, particular items of EEE are deemed WEEE and must be disposed of. Alternatively, other items deemed to retain some value are kept, which places 
these items back at stage 1 .

- Stage four - Divestment: Following a critical moment and categorisation of their hoarded possessions, consumers are often prompted to dispose of their WEEE. WEEE disposal takes place either through appropriate recycling facilities or via other routes. Convenience and familiarity with recycling facilities and practices play an important role in this stage as they determine whether WEEE is recycled or disposed of through other means.



Figure 2 WEEE divestment process

\section{Conclusion and Recommendations}

This research approached WEEE not as a waste stream but as a collection of, sometimes prized, possessions. Possessions are valued for the "meanings they embody, the instrumentalities they provide, and the contributions they make to our well being" $\downarrow$ (Roster, 2001, p. 225). Different levels of attachment to WEEE possessions were manifested due to their perceived use potential, either as devices or parts, and due to an emotional bond with particular "special" objects, or, given the nature of electronics, immaterial objects, such as the data (music, photographs, messages) stored in electronics. People generally store obsolete electronics because of the complex relationship and shifting meaning that WEEE takes on 
within the home rather than due to inaction or lack of information regarding recycling facilities. Significant objects with strong emotional attachment present less of an opportunity but also less of a challenge as they tend to be single objects and do not comprise the bulk of the stored devices.

This initial mapping of the process through which WEEE is kept, confronted and, eventually, disposed of in an Irish home also reveals distinct opportunities, at each stage, for interventions aimed at increasing WEEE recycling. In addition, shortening the cycle in itself is an opportunity for intervention. The findings point towards interventions to a) foster reflexivity around WEEE in the home, b) trigger critical moments and c) introduce convenient facilities for WEEE recycling that can easily become part of consumers' everyday routines. Policymakers should design interventions that tap into the perceived use potential of WEEE or spark a "critical moment". For example, doorstepping campaigns are an effective method of behaviour change which are easily contextualised (Bernstad et al., 2013; Dai et al., 2015). Dai et al. (2015) identified the most successful components of doorstepping campaigns: the impact which participants reported on social norms and emotions, the prompting effect, the visibility of doorsteppers and an increased emphasis on the "community" aspect of the project as opposed to the detrimental environmental effect of not recycling. Doorstepping has never been applied to sWEEE despite being both prudent and effective. A pilot project would present an excellent research opportunity. It is argued that policymaking would benefit from the application of sophisticated approaches to sWEEE collection and related behaviour change. A carefully designed and well delivered doorstepping campaign could addresses the social, cultural and emotional influences which shape consumer disposal behaviour.

Another noteworthy intervention would be the creation and distribution of designated "kits". Each kit would serve to both inform the consumer about local recycling policies (what happens to the discarded EEE) and have a container for storing disused or rarely used electronics and related paraphernalia in the home; the increasing WEEE volume may become a triggering event in itself. Device paraphernalia should also be more clearly demarcated as WEEE. Research indicates that consumers tend to engage more readily with small, non 
consumption based, behavioural changes which take place in the home (Barr and Gilg, 2006), and these kinds of kits have proven effective in the context of food waste. Kitchen caddies have been successfully rolled out in a number of cities (Xevgenos et al., 2015). Finally, an availability of convenient, easily accessible, clearly demarcated public collection points where consumers can comfortably discard their WEEE would, in light of this research, be a more effective means of sWEEE collection. Indeed, a recent study which compares Sweden, Denmark, Germany, Switzerland and Belgium found a reasonable relationship between density of collection sites and WEEE collected $\left(\mathrm{R}^{2}=0.69\right)$ but warns against simplistic transferal of the results as it is likely that there are multiple correlations at play (Friege et al., 2015).

In 2004 Halpern et al. called for policy which would be shaped "around the ways in which people actually think and feel, and the social and psychological forces that influence behaviour" (p. 67). This research contributes to a growing body of research capable of delivering just that. Future research can expand on this aspect in order to further reconcile the policy perspective on WEEE as waste category with consumers' understandings and uses of WEEE in the home. This research focused on the Irish context, which is similar to other European contexts in that consumers tend to stockpile sWEEE. Closer attention to interventions and their capacity to encourage further recycling is also required. Finally, the link between consumers and the circular economy requires exploration. Specifically, research needs to take into account the role of new models of business and consumption, which is understood as "collaborative consumption", and shift towards forms of possession and use that do not involve ownership. Their impact on consumption of sWEEE is yet to be understood.

Acknowledgments: This research is part of a project funded by the Environmental Protection Agency (EPA) Research Programme 2014-2020. The project was co-funded by the EPA, WEEE Ireland, the European Recycling Platform and the Producer Register Limited. The EPA Research Programme is a Government of Ireland initiative funded by the Department of Communications, Climate Action and Environment. 


\section{References}

Abeliotis, K., Christodoulou, D., Lasaridi, K., 2006. Attitudes of consumers on E-waste management in Greece. WIT Trans. Ecol. Environ. 92, 405-414. https://doi.org/10.2495/WM060431

Afroz, R., Masud, M.M., Akhtar, R., Duasa, J.B., 2013. Survey and analysis of public knowledge, awareness and willingness to pay in Kuala Lumpur, Malaysia-a case study on household WEEE management. J. Clean. Prod. 52, 185-193. https://doi.org/10.1016/j.jclepro.2013.02.004

Arnould, E.J., 1998. Daring consumer-oriented ethnography, in: Stern, B.B. (Ed.), Representing Consumers: Voices, Views and Visions. Routeledge, Taylor and Francis Group, London and New York, pp. 85-126.

Arnould, E.J., Wallendorf, M., 1994. Market-Oriented Ethnography: Interpretation Building and Marketing Strategy Formulation. J. Mark. Res. 31, 484-504. https://doi.org/10.2307/3151878

Atkinson, P., 2014. For ethnography 4, 550-568. https://doi.org/10.1007/s13398-014-01737.2

Barr, S.W., Gilg, a, 2006. Sustainable lifestyles: Framing environmental action in and around the home. Geoforum 37, 906-920. https://doi.org/10.1016/j.geoforum.2006.05.002

Beitin, B.K., 2012. Interviewing and Sampling: How Many and Whom?, in: Gubrium, J.F., Holstein, J.A., Marvasti, A.B., McKinney, K.D. (Eds.), The SAGE Handbook of Interview Research: The Complexity of the Craft. Sage Publication Ltd., London, pp. $243-253$.

Belk, R.W., 2013. Extended Self in a Digital World. J. Consum. Res. 40, 477-500. https://doi.org/10.1086/671052

Belk, R.W., 1988. Possessions and the Extended Self. J. Consum. Res. 15, 139-168.

Belk, R.W., Sherry, J.F., Wallendorf, M., 1988. A Naturalistic Inquiry into Buyer and Seller Behavior at a Swap Meet. J. Consum. Res. 14, 449-470. https://doi.org/10.1086/209128

Belk, R.W., Wallendorf, M., Sherry, J.F., 1989. The Sacred and the Profane on in Consumer Behavior: Theodicy on the Odyssey. J. Consum. Res. 16, 1-38. https://doi.org/10.1086/209191

Benton, D., Coats, E., Hazell, J., 2015. A circular economy for smart devices. London. 
Bernstad, A., La Cour Jansen, J., Aspegren, A., 2013. Door-stepping as a strategy for improved food waste recycling behaviour-Evaluation of a full-scale experiment. Resour. Conserv. Recycl. 73, 94-103. https://doi.org/10.1016/j.resconrec.2012.12.012

Bjørnholt, M., Farstad, G.R., 2014. “Am I rambling?” on the advantages of interviewing couples together. Qual. Res. 14, 3-19. https://doi.org/10.1177/1468794112459671

Bouvier, R., Wagner, T.P., 2011. The influence of collection facility attributes on household collection rates of electronic waste: The case of televisions and computer monitors. Resour. Conserv. $\quad$ Recycl. $\quad$ 55, 1051-1059. https://doi.org/10.1016/j.resconrec.2011.05.019

Browne, K., 2005. Snowball sampling: using social networks to research non heterosexual women. Int. J. Soc. Res. Methodol. 8, 47-60. https://doi.org/10.1080/1364557032000081663

Byrne, S., O'Regan, B., 2014. Attitudes and actions towards recycling behaviours in the Limerick, Ireland region. Resour. Conserv. Recycl. 87, 89-96. https://doi.org/10.1016/j.resconrec.2014.03.001

Chi, X., Wang, M.Y.L., Reuter, M.A., 2014. E-waste collection channels and household recycling behaviors in Taizhou of China. J. Clean. Prod. 80, 87-95. https://doi.org/10.1016/j.jclepro.2014.05.056

Dai, Y.C., Gordon, M.P.R., Ye, J.Y., Xu, D.Y., Lin, Z.Y., Robinson, N.K.L., Woodard, R., Harder, M.K., 2015. Why doorstepping can increase household waste recycling. Resour. Conserv. Recycl. 102, 9-19. https://doi.org/10.1016/j.resconrec.2015.06.004

Dalrymple, I., Wright, N., Kellner, R., Bains, N., Geraghty, K., Goosey, M., Lightfoot, L., 2007. An integrated approach to electronic waste (WEEE) recycling. Circuit World 33, 52-58. https://doi.org/10.1108/03056120710750256

Darby, L., Obara, L., 2005. Household recycling behaviour and attitudes towards the disposal of small electrical and electronic equipment. Resour. Conserv. Recycl. 44, 17-35. https://doi.org/10.1016/j.resconrec.2004.09.002

Davies, A.R., Taylor, D., Fahy, F., Meade, H., O’Callaghan-Platt, A., 2005. Environmental Attitudes and Behaviour: Values, Actions and Waste Management. Dublin.

DiGiacomo, A., Wu, D.W.L., Lenkic, P., Fraser, B., Zhao, J., Kingstone, A., 2018. Convenience improves composting and recycling rates in high-density residential 
buildings. J. Environ. Plan. Manag. 61, 309-331. https://doi.org/10.1080/09640568.2017.1305332

Dimitrakakis, E., Janz, A., Bilitewski, B., Gidarakos, E., 2009. Small WEEE: Determining recyclables and hazardous substances in plastics. J. Hazard. Mater. 161, 913-919. https://doi.org/10.1016/j.jhazmat.2008.04.054

Dindarian, A., Gibson, A.A.P., Quariguasi-Frota-Neto, J., 2012. Electronic product returns and potential reuse opportunities: A microwave case study in the United Kingdom. J. Clean. Prod. 32, 22-31. https://doi.org/10.1016/j.jclepro.2012.03.015

Dwivedy, M., Mittal, R.K., 2013. Willingness of residents to participate in e-waste recycling in India. Environ. Dev. 6, 48-68. https://doi.org/10.1016/j.envdev.2013.03.001

Elliott, R., Jankel Elliott, N., Jankel-Elliott, N., 2003. Using ethnography in strategic consumer research. Qual. Mark. Res. An Int. J. 6, 215-223. https://doi.org/10.1108/13522750310495300

Eurostat, 2017. Waste Database. Brussels.

Eutostat, 2014. Environment and Energy. Gener. Treat. waste.

Fraige, F.Y., Al-khatib, L.A., Alnawafleh, H.M., Dweirj, M.K., Langston, P.A., 2012. Waste electric and electronic equipment in Jordan: willingness and generation rates. J. Environ. Plan. Manag. 55, 161-175. https://doi.org/10.1080/09640568.2011.586492

Gurauskienė, I., 2008. The Behaviour of Consumers as One of the Most Important Factors in E-waste Problem. Environ. Res. Eng. ... 4, 56-65.

Gutiérrez, E., Adenso-Díaz, B., Lozano, S., González-Torre, P., 2011a. Lifetime of household appliances: empirical evidence of users behaviour. Waste Manag. Res. 29, 622-633. https://doi.org/10.1177/0734242X10377914

Gutiérrez, E., Díaz, B.A., Lozano, S., Moreno, P., 2011b. An exploratory study of Spanish households' WEEE disposal behaviour. Int. J. Soc. Syst. Sci. 3, 385. https://doi.org/10.1504/IJSSS.2011.043214

Halpern, D., Bates, C., Mulgan, G., Aldridge, S., Beales, G., Heathfield, A., 2004. Personal Responsibility and Changing Behaviour: the state of knowledge and its implications for public policy.

Heaphy, B., Einarsdottir, A., 2013. Scripting Civil Partnerships: interviewing couples together and apart. Qual. Res. 13, 53-70. https://doi.org/10.1177/1468794112454997 
Hertz, C., 2011. Costuming Potential: Accommodating Unworn Clothes. Museum Anthropol. Rev.

Islam, M.T., Abdullah, A.B., Shahir, S.A., Kalam, M.A., Masjuki, H.H., Shumon, R., Rashid, M.H., 2016. A public survey on knowledge, awareness, attitude and willingness to pay for WEEE management: Case study in Bangladesh. J. Clean. Prod. 137, 728-740. https://doi.org/10.1016/j.jclepro.2016.07.111

Kleine, S.S., Baker, S.M., 2004. An Integrative Review of Material Possession Attachment. Acad. Mark. Sci. Rev. 2004, 1.

La Barbera, F., Del Giudice, T., Sannino, G., 2014. Are people willing to pay for waste prevention? the moderating role of environmental attitude. Qual. - Access to Success 15, $213-218$.

Ladner, S., 2014. Practical ethnography : a guide to doing ethnography in the private sector. Left Coast Press, Walnut Creek, CA.

Lastovicka, J.L., Fernandez, K. V., 2005. Three Paths to Disposition: The Movement of Meaningful Possessions to Strangers 31.

Li, B., Yang, J., Song, X., Lu, B., 2012. Survey on Disposal Behaviour and Awareness of Mobile Phones in Chinese University Students. Procedia Environ. Sci. 16, 469-476. https://doi.org/10.1016/j.proenv.2012.10.064

Li, J., Liu, L., Ren, J., Duan, H., Zheng, L., 2012. Behavior of Urban Residents Toward the Discarding Of Waste Electrical and Electronic Equipment: A Case Study in Baoding, China. Waste Manag. Res. 30, 1187-1197. https://doi.org/10.1177/0734242X12456728

Makov, T., Font Vivanco, D., 2018. Does the Circular Economy Grow the Pie? The Case of Rebound Effects From Smartphone Reuse. Front. Energy Res. 6, 1-11. https://doi.org/10.3389/fenrg.2018.00039

Martin, M., Williams, I.D., Clark, M., 2006. Social, cultural and structural influences on household waste recycling: A case study. Resour. Conserv. Recycl. 48, 357-395. https://doi.org/10.1016/j.resconrec.2005.09.005

Martinho, G., Magalhães, D., Pires, A., 2017. Consumer behavior with respect to the consumption and recycling of smartphones and tablets: An exploratory study in Portugal. J. Clean. Prod. 156, 147-158. https://doi.org/10.1016/j.jclepro.2017.04.039

McCoole, F., Kurz, I., Reilly, J., Searson, H., O’Neill, D., McDonagh, M., 2014. National 
Waste Report 2012. Environmental Protection Agency, Dublin.

McCracken, G., 1986. Culture and Consumption : A Theoretical Account of the Structure and Movement of the Cultural Meaning of Consumer Goods. J. Consum. Res. 13, 71-84.

Nixon, H., Saphores, J.-D.M., 2007. Financing electronic waste recycling Californian households' willingness to pay advanced recycling fees. J. Environ. Manage. 84, 547559. https://doi.org/10.1016/j.jenvman.2006.07.003

Nnorom, I.C., Ohakwe, J., Osibanjo, O., 2009. Survey of willingness of residents to participate in electronic waste recycling in Nigeria - A case study of mobile phone recycling. J. Clean. Prod. 17, 1629-1637. https://doi.org/10.1016/j.jclepro.2009.08.009

Ongondo, F.O., Williams, I.D., 2011a. Mobile phone collection, reuse and recycling in the UK. Waste Manag. 31, 1307-1315. https://doi.org/10.1016/j.wasman.2011.01.032

Ongondo, F.O., Williams, I.D., 2011b. Greening academia: Use and disposal of mobile phones among university students. Waste Manag. 31, 1617-1634. https://doi.org/10.1016/j.wasman.2011.01.031

Pérez-Belis, V., Braulio-Gonzalo, M., Juan, P., Bovea, M.D., 2017. Consumer attitude towards the repair and the second-hand purchase of small household electrical and electronic equipment. A Spanish case study. J. Clean. Prod. 158. https://doi.org/10.1016/j.jclepro.2017.04.143

Price, L.L., Arnould, E.J., Folkman Curasi, C., 2000. Older Consumers' Disposition of Special Possessions. J. Consum. Res. 27, 179-201. https://doi.org/10.1086/314319

Rook, D.W., 1985. The Ritual Dimension of Consumer Behavior. J. Consum. Res. 12, 251264. https://doi.org/10.1086/208514

Roster, C., 2001. Letting go: The process and meaning of dispossession in the lives of consumers. Adv. Consum. Res. 28, 425-430. https://doi.org/10.1590/1516-4446-20161953

Saphores, J.-D.M., Nixon, H., Ogunseitan, O.A., Shapiro, A.A., 2007. California households' willingness to pay for 'green' electronics. J. Environ. Plan. Manag. 50, 113-133. https://doi.org/10.1080/09640560601048549

Saphores, J.-D.M., Nixon, H., Ogunseitan, O.A., Shapiro, A.A., 2006. Household Willingness to Recycle Electronic Waste: An Application to California. Environ. Behav. 38, 183-208. https://doi.org/10.1177/0013916505279045 
Saritha, V., Sunil-Kumar, K.A., Srikanth, V.N., 2015. Consumer Attitudes and Perceptions on Electronic Waste: An Assessment. Pollution 1, 31-43.

Sivathanu, B., 2016. User' s Perspective: Knowledge and Attitude towards. Int. J. Appl. Environ. Sci. 11, 413-423.

Song, Q., Wang, Z., Li, J., 2016. Residents' Attitudes and Willingness to Pay for Solid Waste Management in Macau. Procedia Environ. Sci. 31, 635-643. https://doi.org/10.1016/j.proenv.2016.02.116

Speake, J., Nchawa Yangke, L., 2015. "What Do I Do With My Old Mobile Phones? I Just Put Them in a Drawer": Attitudes and Perspectives Towards The Disposal of Mobile Phones in Liverpool, UK. Hum. Geogr. -Journal Stud. Res. Hum. Geogr. 9, 241-260. https://doi.org/10.5719/hgeo.2015.92.8

Spradley, J.P., 1979. The Ethnographic Interview.

Valentine, G., 1999. Doing Household Research: Interviewing Couples Together and Apart. Area 31, 67-74. https://doi.org/10.1111/j.1475-4762.1999.tb00172.x

Wang, Z., Zhang, B., Yin, J., Zhang, X., 2011. Willingness and behavior towards e-waste recycling for residents in Beijing city, China. J. Clean. Prod. 19, 977-984. https://doi.org/10.1016/j.jclepro.2010.09.016

WEEE Ireland, 2017a. Annual Environmental Report 2016. Dublin.

WEEE Ireland, 2017b. Annual Environmental Report 2016. Dublin.

WEEE Ireland, 2016. Annual Report 2015. Dublin.

Welfens, M.J., Nordmann, J., Seibt, A., 2016. Drivers and barriers to return and recycling of mobile phones. Case studies of communication and collection campaigns. J. Clean. Prod. 132, 108-121. https://doi.org/10.1016/j.jclepro.2015.11.082

Wilkinson, S., Duffy, N., 2003. Waste Electrical and Electronic Equipment (Weee) Collection Trials in Ireland. Environ. Prot.

Wilson, G.T., Smalley, G., Suckling, J.R., Lilley, D., Lee, J., Mawle, R., 2017. The hibernating mobile phone: Dead storage as a barrier to efficient electronic waste recovery. Waste Manag. 60, 521-533. https://doi.org/10.1016/j.wasman.2016.12.023

Xevgenos, D., Papadaskalopoulou, C., Panaretou, V., Moustakas, K., Malamis, D., 2015. Success Stories for Recycling of MSW at Municipal Level: A Review. Waste and Biomass Valorization 6, 657-684. https://doi.org/10.1007/s12649-015-9389-9 
Ylä-Mella, J., Keiski, R.L., Pongrácz, E., 2015. Electronic waste recovery in Finland: Consumers' perceptions towards recycling and re-use of mobile phones. Waste Manag. 45, 374-384. https://doi.org/10.1016/j.wasman.2015.02.031

Ylä-Mella, J., Poikela, K., Lehtinen, U., Tanskanen, P., Román, E., Keiski, R.L., Pongrácz, E., 2014. Overview of the WEEE Directive and Its Implementation in the Nordic Countries : National Realisations and Best Practices. J. Waste Manag. 2014, 18.

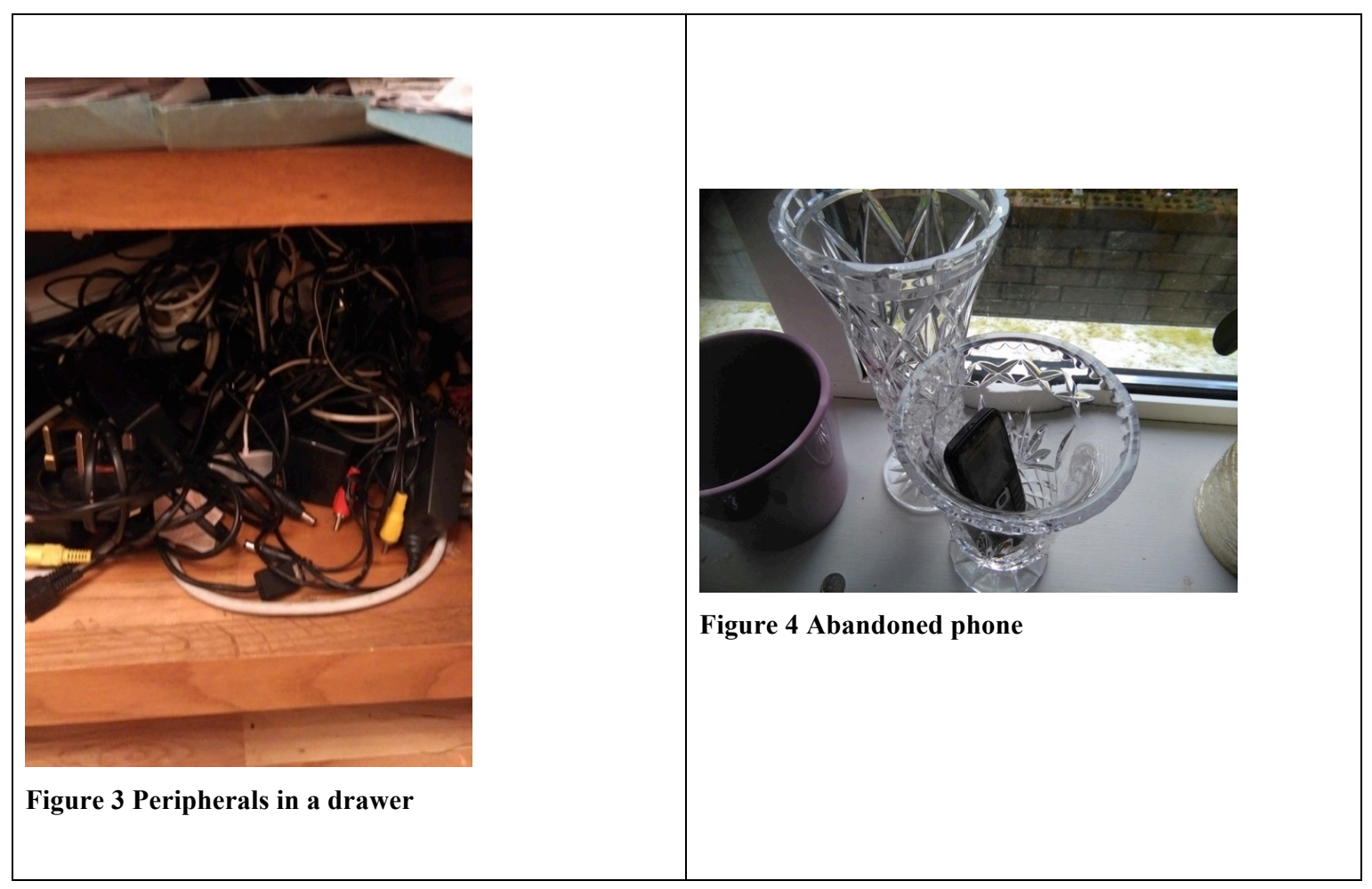




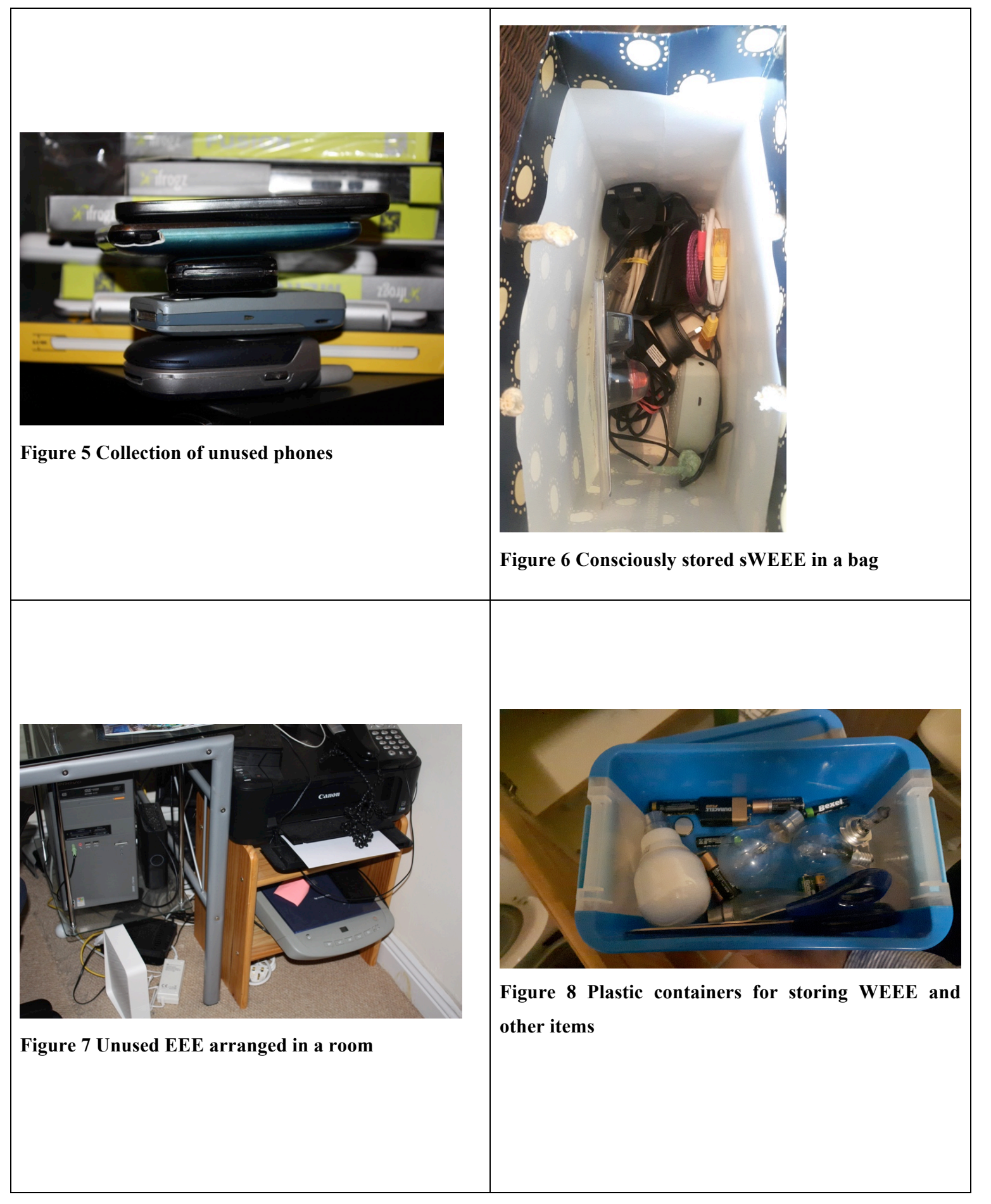




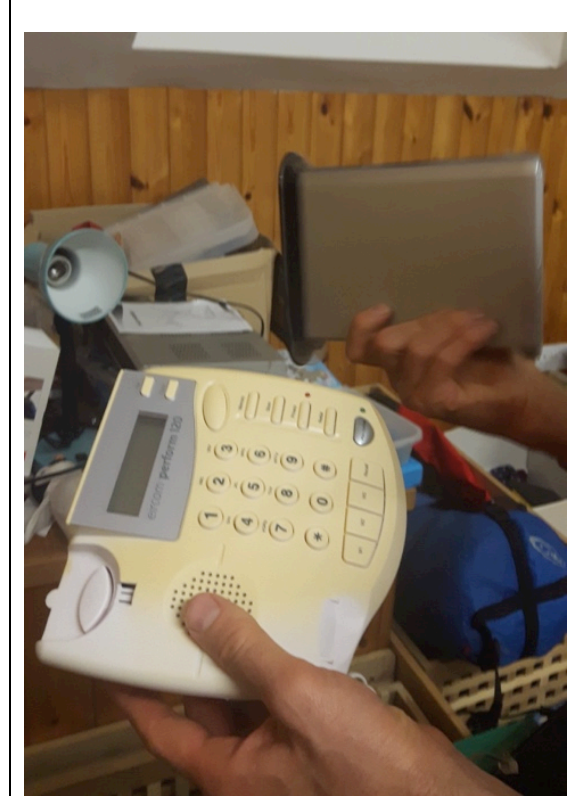

Figure 9 Carefully stored WEEE

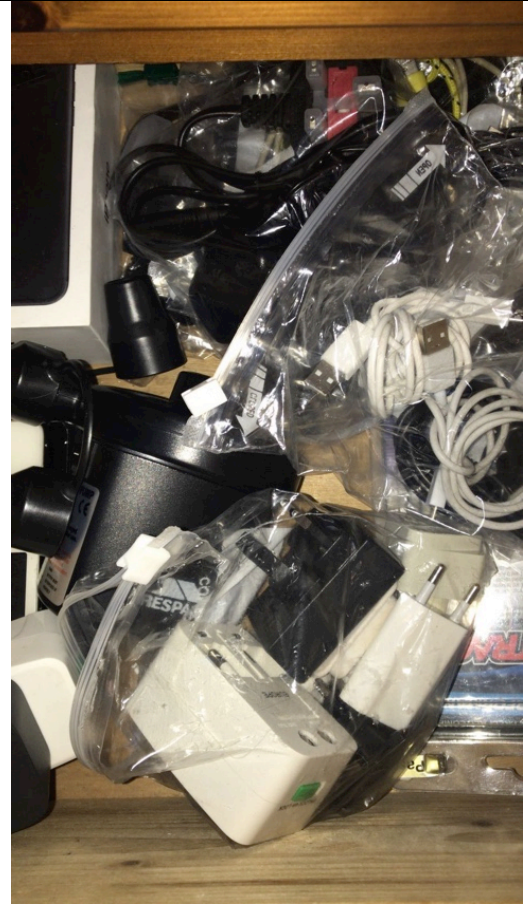

Figure 10 Unused peripherals 